International Journal of Applied Linguistics \& English Literature

ISSN 2200-3592 (Print), ISSN 2200-3452 (Online)

Vol. 1 No. 7; November 2012 [Special Issue on Applied Linguistics]

\title{
Speech Disfluencies and Mispronunciations in English Oral Communication among Malaysian Undergraduates
}

\author{
Sarah Yong Enxhi \\ Department of English \\ Faculty of Modern Languages and Communication \\ Universiti Putra Malaysia \\ Tan, Bee Hoon (Corresponding author) \\ Department of English \\ Faculty of Modern Languages and Communication \\ Universiti Putra Malaysia \\ E-mail: tanbh@fbmk.upm.edu.my \\ Yong, Mei Fung \\ Department of English \\ Faculty of Modern Languages and Communication \\ Universiti Putra Malaysia
}

Received: 20-10- 2012

doi:10.7575/ijalel.v.1n.7p.19
Accepted: 22-11- 2012

Published: 25-11- 2012

URL: http://dx.doi.org/10.7575/ijalel.v.1n.7p.19

\begin{abstract}
The common perception of Malaysians is that they are unable to speak fluently and communicate effectively in the English language as most Malaysians do not speak English as their first language. In a country that is full of diversity in terms of race and culture, it is only natural for Malaysians to be influenced by their first language when using English as their second language. This, however, creates a problem for undergraduates who are looking for job opportunities in both local and international companies because a potential employee's ability to communicate smoothly in English is an important criteria used by employers. This study intends to shed light on the occurrence of speech disfluencies and mispronunciations among undergraduates of a Malaysian university as well as to provide an explanation for those mispronunciations by comparing the phonetic system of the English language with the Malay and Mandarin language. With the results of this study, it is hoped that actions and measures can be taken by the academic authorities and other relevant parties to gradually improve the oral proficiency skills of undergraduates and help them to be more marketable in the future.
\end{abstract}

Keywords: Speech disfluencies, mispronunciations, oral communication, second-language acquisition

\section{Background of the study}

JobStreet, the largest online employment company in Southeast Asia, conducted a survey in August 2009 to gauge the importance of the English language in the workplace (Jobstreet, 2009). This study, which involved 1001 employers, concluded that $92 \%$ of employers agreed that conversational English is the most important when it came to looking for new hires. Hopeful candidates who are interested in getting a job do not even stand a fighting chance if they are not able to communicate well in English because the most popular method (84\%) to screen potential hires is by a face-to-face interview. Therefore, fresh graduates must be able to converse and interact accurately in English if they want a brighter future in their career.

\subsection{Statement of the problem}

The decline of the performance of English communication skills among Malaysian university students is becoming a serious problem in the country. According to the Vice Chancellor of Universiti Putra Malaysia (UPM), out of the total of 6, 946 undergraduates who finished their tertiary programme last year, only 4, 478 of them were able to obtain a job. UPM had actually originally predicted that there would be approximately $78 \%$

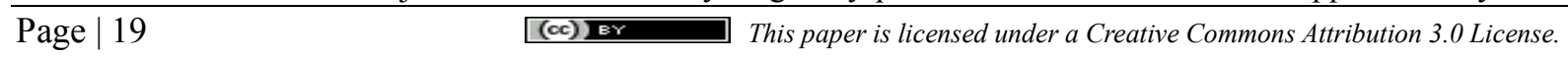




\section{International Journal of Applied Linguistics \& English Literature}

ISSN 2200-3592 (Print), ISSN 2200-3452 (Online)

Vol. 1 No. 7; November 2012 [Special Issue on Applied Linguistics]

chance of undergraduates getting employed within 6 months after their graduation; however, the actual figure has now dropped to below 65\% (Komunitikini, 2011). Comparing previous and current statistics, if this downward trend continues without abatement, the number of unemployed graduates in the future will surely continue to rise.

Linguists may debate over the exact factor that has influenced the level of performance of English communication among local university students. Since most students are not native English speakers, that itself is already one of the main factors in this area of concern. In families that speak Malay or Chinese as their first language, students are not able to practice speaking English as often as they may want to. This in turn will affect students' confidence in speaking in English and their level of proficiency in English can be evaluated through the Test of Communication in English (TOCIE) carried out in Universiti Putra Malaysia. However, social background and first language of students are factors that cannot be changed as the students' first language is something that is learned at a young age. Linguistic factors, however, such as mispronunciation, stuttering, and other slips of the tongue, are factors that can be identified in order to improve the level of English oral communication among university students.

In an effort to find out the basic linguistic factors which affect the students' fluency of speech, this research paper focuses on two elements of oral communication: speech disfluencies and mispronunciations.

\subsection{Objectives and research questions of the study}

There are three specific objectives in this research. The first specific objective is to determine the speech disflencies which commonly occur in English oral communication among UPM TOCIE candidates. The second specific objective is to determine the mispronunciations in English oral communication among UPM TOCIE candidates. The third and final specific objective is to identify the factors that influence the occurrence of mispronunciations in English oral communication among UPM TOCIE candidates.

From the specific objectives, three research questions are formulated:

1. What are the speech disfluencies which commonly occur in English oral communication among UPM undergraduates?

2. What are the mispronunciations in English oral communication among UPM undergraduates?

3. What are the linguistic factors contributing to the mispronunciations in English oral communication among UPM undergraduates?

\subsection{Significance of the study}

Speech disfluencies and mispronunciations should not be looked down upon because although 'to err is human', there is no excuse for mispronunciation, unless one is poorly educated, intend to insult, or cannot win at war (Andrews, 2006). The third specific objective of this research paper focuses on the factors that influence mispronunciations because it is an error that can be easily rectified with awareness and proper correction.

It is hoped that the results of this study will be able to cast some light on the common speech disfluencies and mispronunciations among Malaysian undergraduates, using the final year students from Universiti Putra Malaysia as a sample to represent Malaysian undergraduates as a whole. Besides that, it is also hoped that through this research, undergraduates will become aware of the linguistic factors that influence their mispronunciations. By knowing the linguistic factors that is affecting their mispronunciations, they will be able to practice avoiding those mistakes consciously and then continue to improve their English pronunciation skills.

\subsection{Definition of key terms}

At this juncture, there are a few terms used in the title of this research that should be defined for clarity purposes.

Speech disfluencies happen when there are breaks, irregularities, or non-lexical words that interrupt the flow of fluent speech. Some types of speech disfluencies are false starts, fillers, whereby words and sentences are cut off in mid-utterance, phrases are restarted, or syllables are repeated; fillers, grunts, and non-lexical utterances, such as $u h$, erm, and well. In this research paper, the types of disfluencies discussed follow Shriberg's (1994) paper as shown in Table 1.

Mispronunciations are when a word is produced with the wrong sound output. Donselaar (1996) defines mispronunciation as inappropriate phonemes in the place of an original phoneme in a word. In Malaysia, although Malaysian English is descended from British English, American English is also accepted due to its influence on the mass media. Therefore, in this research paper pronunciations from both British and American 
International Journal of Applied Linguistics \& English Literature

ISSN 2200-3592 (Print), ISSN 2200-3452 (Online)

Vol. 1 No. 7; November 2012 [Special Issue on Applied Linguistics]

English will be accepted. Pronunciations that are not in tandem with either form of English are considered to be mispronunciations.

Table 1. Disfluency types

\begin{tabular}{|l|l|}
\hline \multicolumn{1}{|c|}{ Disfluency type } & \multicolumn{1}{c|}{ Example } \\
\hline Filled pause & uh-we live in Dallas \\
\hline Repetition & all the - the tools \\
\hline Deletion & it's - I could get it where I work \\
\hline Substitution & any health cover - any health insurance \\
\hline Insertion & and I felt - I also felt \\
\hline Articulation error & and [pin] - pistachio nuts \\
\hline
\end{tabular}

TOCIE was introduced in Universiti Putra Malaysia in 2011 and it was made compulsory for all final year students from all faculties (FBMK, 2011). The main objective of TOCIE is to assess the English communication skills of the candidates in order to determine their proficiency level in using this skill in their potential workplace no matter the field of study they are involved in. The candidates were given 20 minutes to hold a discussion among themselves ( 5 candidates in a group) based on a topic that is given to them. The candidates were evaluated based on 4 main criteria, which are accuracy, appropriacy, use of language functions, and managing a discussion.

\section{Literature review}

\subsection{Importance of Oral Communication}

Oral communication is necessary for people to function in an efficient manner in a work environment (Crosling \& Ward, 2002). Due to this need, courses which incorporate oral communication activities are included in university programmes so that graduates are more prepared for the world of work. Some students may only focus on English writing and are thus able to excel in examinations. Nonetheless, it is actually applying the English language in real life situations that is more challenging.

One interesting study carried out by Hughes and Large (1993) point out that one's communication skill may not be necessarily reflected in one's performance in written tests. A total of 45 final year BSc pharmacology students from the University of Leeds were required to give a 10-12 minute presentation as part of their assessment. After collecting the marks given to each student, a comparison was made between the communication skills and the performance in written essays and examinations of the students. There are a few students who display positive results in both written and oral areas with the assumption that those are the students who are motivated enough to excel with a more wholesome approach; however, there are students who are 'good writers but poor talkers'. This proves that there is a need for a separate test or indicator to assess students' oral communicative skills because their actual level of performance cannot be accurately retrieved or predicted from their exam results every semester.

The research mentioned above supports the need for oral communication in the form of formal presentations. However, there are studies that also express the importance of informal oral communication, even in the workplace (Crossling \& Ward, 2002; Hughes \& Large, 1993). Formal presentation is a form of communication that is deductive, which according to Scollon and Scollon (1995), concerns a situation whereby the topic of discussion is first introduced and then it is followed by points that reinforce or contribute to that particular topic.

A survey that was conducted by Crosling and Ward (2002) affirms the proposition that informal oral communication is equally, if not more, crucial in a workplace. This is because communication is context-dependent and effective communication is based on how quickly one responses and how suitable the response is within the discourse community (Bizzell, 1989). Therefore, university education needs to include oral communication activities that involve the use of informal interaction in the English language so that it provides students the opportunity to polish their informal oral communication skills besides the usual formal presentation skills.

Unfortunately, even with so many researches and surveys done to increase awareness regarding the importance of effective and accurate oral communication, not much has been done by colleges and universities to reduce the problem. In fact, it is the alumni, employers, and graduates themselves who are more aware of this problem as compared to how much the college faculties and administration staff are (Samuel \& Leah, 1979). Fresh 
International Journal of Applied Linguistics \& English Literature

ISSN 2200-3592 (Print), ISSN 2200-3452 (Online)

Vol. 1 No. 7; November 2012 [Special Issue on Applied Linguistics]

graduates are still facing unemployment due to their lack of competence in oral communication. 2.2 Importance of Pronunciation It has already been established that oral communication is important, it should be noted that spoken words never involve spelling, instead they involve pronunciation. It is possible that the occurrence of mispronunciations may have emerged from the students' lack of interest. They probably feel that pronunciation is not as important as other linguistics elements of a language such as grammar and vocabulary. Cenoz and Lecumberri (1999) mentioned that sometimes pronunciation may be given less attention in a language syllabus as it serves just as a supplementary activity. This of course does not discountenance the importance of pronunciation since language is frequently spoken in contrast with written.In an effort to test this hypothesis and compare learners' attitude towards grammar, pronunciation, and vocabulary, Simon and Taverniers (2011) conducted a research study involving tertiary English language students in Flanders, a Belgian university. A total of 117 first year students who are native speakers of Dutch completed the extensive questionnaire consisting of semantic scale and Likert scale questions which sought to determine the subjects' views on the importance of grammar, pronunciation, and vocabulary. Results indicate that learners felt that all the three aspects (grammar, pronunciation, and vocabulary) are almost equally important to achieve a native-like competence in the language and that all of those elements could somewhat contribute to a communication breakdown if used incorrectly with an English native speaker. However, although they agree that all the three elements are of equal importance, it should be noted that the results reveal that learners perceived learning the pronunciation requires less effort in comparison to learning the vocabulary. This perception could be linked to the mispronunciations that occur among students; they think that it is easier, so they put less effort and time to learn it properly.2.3 Background of Malaysian Oral EnglishAs Toolan (1997) observes, as with any other language which is wide-spread and greatly used, English evolves according to geographical location, cultural and political influence. The evolution of the English language produces new varieties that make it distinct from the original variety. Platt et al. (1984) referred to this variety as the 'New Englishes'. Other researches introduced the variety as 'Local Forms of English' (Strevens, 1992), and 'Anglo-hybrids' (McArthur, 1998). The creation of a language with the localised linguistic features is called nativisation (Kachru, 1986). The phenomenon of nativisation can be seen clearly in Malaysia. Through the mixture of many different ethnicities, races, and indigenous dialects, the use of English as a lingua franca has induced the growth and evolution of the Malaysian variety of English which is now famously known as 'Manglish' (Baskaran, 1994). Benson (1990) differentiated three categories of Malaysian English which are varied by speakers and degree of formality; Anglo-Malay, Colloquial Malaysian English, and Malay-influenced Malaysian English. Some speakers who are more fluent in the language are also able to switch from one variety to another, depending on the context of use. For example, when speaking in a more formal context, those speakers are able to adjust their accent to be less ethnically marked; so much so that when a test was conducted to see if listeners could tell the ethnicity of the speakers apart by listening to their pronunciation, more than half the time, their guesses were wrong (Pillai, Knowles \& Mohd. Don, 2001). Perhaps, it is this distinction that encourages people to make the effort to consciously change their accent in certain situations as it is able to alter the listener's perception of the speaker. This is reflected in another study carried out by Phillip, Pillai and Jeyam (2007) which show that from a total of 89 Malaysian undergraduates, half of them recognized that they speak with a Malaysian accent; however, only $29 \%$ of them admitted that their local accent is acceptable. It is undeniable that 'Malaysian English' should be recognized as a unique language variety which has been localized and adjusted to adapt and suit the local needs of Malaysians (Rajadurai, 2004). However, the question is even with the use of the Malaysian accent and features of Malaysian English: are speakers still able to speak the English language accurately with less speech disfluencies and mispronunciations in formal interactions?

\subsection{Speech Disfluencies in Spoken English}

Speech disfluency is a linguistic term that refers to the occurrence of interruptions or momentary disruptions during the flow of speech but does not contribute any semantic or propositional content to the speech (Fox Tree, 1995). Disfluencies are present during conversations among people, especially in spontaneous interaction. There are a few types of disfluency based on the work of Postma, Kolk, and Povel (1990) such as repetitions, prolongations of sounds, blocking on sounds, and interjections of meaningless sounds. Repetitions include repeating syllables, words, and phrases. There are a few uncertainties on whether pauses are considered as a form of disfluency; however according to Fox Tree (1995), pauses should be excluded and therefore it can be estimated that $6 \%$ of every 100 words are disfluencies.

Logically, if syntactically plausible words can lengthen the time taken for comprehension, then non-syntactic words like disfluencies should have larger negative effects. Another research that also predicted that disfluencies should negatively affect one's comprehension is by Marslen-Wilson and Tyler (1980). Results show that a noun 
International Journal of Applied Linguistics \& English Literature

ISSN 2200-3592 (Print), ISSN 2200-3452 (Online)

Vol. 1 No. 7; November 2012 [Special Issue on Applied Linguistics]

could be identified faster in a normal sentence instead of sentences that are implausible, and this led to the conclusion that semantic and syntactic nonsense like disfluencies should also delay comprehension.

However, in contrast to the earlier research mentioned, Fox Tree (1995) sought to prove that the effect of speech disfluencies (false starts and repetitions) can vary according to its type and position in a spoken sentence. In order to determine the effect of speech disfluencies with the position and type as a variable, the time that it took for the participants to identify the first viable target words after the disfluencies was compared to the time taken by participants to identify the same items when the disfluencies were taken out of the speech stream and replaced by either a pause (Experiment 1) or deleted entirely (Experiment 2). According to the results, identification of words takes a longer time when there are false starts present; however, this is not the case for repetitions. Also, the more disrupted the syntax of a sentence is, the more effort is used in the repair process of the sentence. Therefore, if the false start is located at the beginning of the sentence, the listener can simply abort the false start and the repair process is less costly. Although repetitions do not create disruptions like false starts, it perhaps might cause some form of distraction to listeners.

\subsection{Mispronunciations in Spoken English}

Researchers have carried out various studies to attempt to categorize the types of mispronunciations. Bonaventura, Herron, and Menzel (2000) state three types of mispronunciation that are categorized based on distinguished problem areas: problems in the pronunciation of non-native sounds; carry-over of pronunciation regularities from the mother tongue (L1); and overgeneralizations of target language (L2) regularities. Speakers will replace phonemes that do not exist in their original mother tongue (L1) with the closest-sounding phoneme from their native language. An example would be a common mispronunciation by Germans when speaking the English language which is the replacement of the [w] with [v]; therefore, with is pronounced as vith.

The second type of mispronunciation, which is the carry-over of pronunciation regularities, involves mostly phonological changes, such as the devoicing of final voiced stop consonants or the spelling-to-sound mapping of the mother tongue. Devoicing of final voiced stop consonants occur when Germans mispronounce banned by changing the [d] to a [t]; whereas spelling-to-sound mapping takes place when Italians mispronounce the [y] in sing as two separate phones $[\mathrm{n}]$ and $[\mathrm{g}]$ because it aligns with their mother tongue's orthography.

The third type of mispronunciation is when a speaker applies a possible pronunciation in an unsuitable word For example, when the /g/ in angry is mispronounced as /dz/ in judge. Bonaventura, Herron, and Menzel (2000) did not include co-articulation errors in the research. Co-articulation errors includedeletions or assimilations of initial and final consonants or vowels when the adjacent phones influence each other. However, these sorts of error are looked at in this paper.

The detection of mispronunciations is often influenced by the number of errors that are present in a word or phrase. Another factor that influences the detection of a mispronunciation is the position of the mispronunciation. It was noticed that when the mispronunciation occurred in the first syllable of the word, the listener took a longer time to detect the error. Donselaar (1996) makes similar findings whereby initial deviations in a word are detected less often compared to deviations located in the middle or at the end of a word. Besides that, listeners finding that accented deviations are easier to detect than unaccented deviations. This might suggest that the mispronunciations by a non-native speaker may be more obvious than mistakes done by a native speaker and therefore, non-native speakers will have to put in extra efforts to communicate effectively with native speakers.

\subsection{Influence of L1 on L2}

One main concern is whether the other languages have a negative effect on the speakers' oral English performance in terms of intelligibility and reputation on the international stage. After all, it is important for non-native speakers to grasp the phonological system of the second language to be fluent. This includes the sounds and intonation of the language (Van Weeren \& Theunissen, 1987). The effect of some of the locals' first language on their English oral proficiency, such as Bahasa Malaysia and Mandarin, are discussed in this paper because it is a factor that is non-negligible in the occurrence of speech disfluencies and mispronunciations.

The occurrence of mispronunciations among L2 learners correlates with the phonetic differences between the learners' L1 and L2. Flege (1993) explains that when there are sounds that do not exist in one's L1, it is replaced with similar sounds that do exist in one's L1 when using the L2. There are several theories that explain the influence of L1 on the learners of L2. A few of these theories are mentioned by Fu (2010): the Critical Period Hypothesis (CPH) (Lenneberg, 1967), the theory of language transfer (interference of L1) (Gass \& Selinker, 1972), the Contrastive Analysis Hypothesis (CA) (Lado, 1957), and the Markedness Differential Hypothesis 
International Journal of Applied Linguistics \& English Literature

ISSN 2200-3592 (Print), ISSN 2200-3452 (Online)

Vol. 1 No. 7; November 2012 [Special Issue on Applied Linguistics]

(MDH) (Eckman, 1977).

The Critical Period Hypothesis was originally introduced by Penfield and Roberts (1959) and it asserts that it becomes difficult for speakers to achieve native-like fluency in L2 if the second language is learnt after the learner passes puberty. Silverberg and Samuel (2004) tested the CPH and conclude that the most obvious finding is that the rate of second language acquisition does decline steadily throughout one's lifespan although age is not the only factor that contributes to this decline. The Theory of Language Transfer presents another viewpoint, which that is there can be two types of transfers as a consequence of the L2 learners using their knowledge of L1 within an L2 context. This results in either a positive transfer or a negative transfer, and this transfer can occur from L1 to L2 or vice versa (Cook, 2003). This is seen in Chinese speakers who have difficulties pronouncing / $\theta /$ and / $/$ / because those sounds are not in their L1 phonological system (Major \& Faudree, 1996). The Contrastive Analysis Hypothesis is almost similar to the Theory of Language Transfer, which is that the more similar L1 sounds are to L2, the easier it is for learners to acquire the language accurately (Lado, 1957). Lastly, the Markedness Differential Hypothesis explains the gaps that the Contrastive Analysis Hypothesis cannot, which is the production of sound substitutions that do not exist in both L1 and L2 (Eckman, 1977).

These theories provide proof that there is a relationship that exist between the phonological systems of L1 and L2 and as long as non-native speakers of a language do not control the influences of their L1 on their acquisition and usage of L2, features of L1 will remain prominent in their speech and they will find it difficult to be fully proficient in the language (Flege, 1993).

\section{Methodology}

\subsection{Participants}

This research adopts a qualitative approach. A qualitative research does not necessarily need a large sample population; therefore, out of the total number of TOCIE candidates, a small sample was chosen by probability cluster sampling. According to Lee, Forthoferm, and Lorimer (1989), this type of sampling method is a practical approach because it samples by groups instead of individual elements (). This sampling method was chosen is because it is easier to divide the population of TOCIE candidates into clusters based on their topic of discussion instead of any other variables. One of the clusters was randomly chosen as the subjects of the study by simple random sampling. The topic of discussion for this cluster is "Ways to improve thinking skills among university students." Participants are of different races: mainly Malay, Chinese, and Indian. The respondents who participated in the research were final year students from different faculties in UPM.

\subsection{Research Instruments}

The instrument used in the study is the TOCIE test. The test was introduced in Universiti Putra Malaysia in 2011 and it was made compulsory to all final year students from all faculties. The main objective of TOCIE is to assess the English communication skills of the students in order to determine their proficiency level in using this skill in their potential workplace. The candidates are given 20 minutes to hold a discussion among themselves (5 candidates in a group) based on a topic that is given to them. The candidates will be evaluated based on 4 main criteria, namely, accuracy, appropriacy, use of language functions, and managing a discussion.

The students' discussions were also audio-recorded. This is to enable analysis to be carried out more rigorously and in a detailed manner since the audio-recordings could be played-back as many times as needed for the data to be transcribed.

Another instrument, the computer software Audacity 1.3 Beta, was used to listen to the audio recordings. Audio recordings of the TOCIE discussion was opened with Audacity 1.3 Beta so that when the speech of the TOCIE participants is too high, the speed or pitch of the recording can be altered so that it can be heard more clearly.

\subsection{Research Procedure}

While TOCIE candidates discussed the topic that was given to them, they were recorded with a tape recorder. Each recording lasts about 15 to 20 minutes, which is the duration of each discussion. After that each recording was transcribed following Baars, Motley and MacKay (1975). The utterances that were recorded on tape are listened to repeatedly in order to transcribe as accurately as possible. Each transcription is verbatim, including all pauses, fillers, and mispronunciations. Symbols are used to represent discourse elements; the transcription symbols are adapted from Talk in action: Interactions, identities, and institutions by Heritage and Clayman (2010) as shown in Tables 2, 3, and 4.

After the transcribing process is complete, the transcriptions were analysed, each speech difluency and 
International Journal of Applied Linguistics \& English Literature

ISSN 2200-3592 (Print), ISSN 2200-3452 (Online)

Vol. 1 No. 7; November 2012 [Special Issue on Applied Linguistics]

mispronunciation was noted to achieve the first and second specific objective of this research. For the third specific objective, a comparison was made between the linguistic features of English, Bahasa Malaysia, and Mandarin that may explain the mispronunciations that are made by the students.

\subsection{Data Analysis Method}

By using the Contrastive Analysis Hypothesis (CA) (Lado, 1957) and the Theory of Language Transfer (Gass \& Selinker, 1972), the phonetic and phonological differences that exist between the languages were used to come up with an explanation to the occurrences of these mispronunciations.

Table 2. Transcription Symbols for Temporal and Sequential Relationships

\begin{tabular}{|l|}
\hline Temporal and Sequential Relationships \\
\hline$\left[\quad \begin{array}{l}\text { Separate left square brackets which are located above one another in two successive } \\
\text { utterances by different speakers show that the utterances are overlapping, whether } \\
\text { it is at the beginning of a speech or in between. }\end{array}\right.$ \\
Equal signs are commonly used in pairs, either at the end of a line or the start of \\
another. They can be used in two situations: \\
(1) If the equal signs are used by the same speaker that means the utterance of the \\
speaker was continuous and constant even though there are interruptions during \\
the speech such as overlapping talk. \\
(2) If the equal signs are used by different speakers that means the two utterances by the \\
two speakers have been combined with no pauses in between; the second \\
utterance was 'latched' on the first one. \\
Two periods located one after another indicates a short pause or break in utterance, \\
about half a second in duration. \\
Three periods located one after another indicates a pause or silence, more than a second \\
in duration but less than five seconds
\end{tabular}

Table 3. Transcription Symbols for Aspects of Speech Delivery

\begin{tabular}{|c|}
\hline Aspects of speech delivery, including aspects of intonation \\
\hline $\begin{array}{l}\text { A punctuation mark is used to indicate that there is a falling intonation of the morpheme } \\
\text { which shows finality, usually occurs at the end of a sentence. }\end{array}$ \\
\hline A comma is used to indicate an intonation of continuity. \\
\hline A question mark indicates a rising intonation, usually representing the end of a \\
question.
\end{tabular}

Table 4. Transcription Symbols for Other Markings

\begin{tabular}{|c|c|c|}
\hline \multicolumn{3}{|c|}{ Other markings } \\
\hline$(($ & & $\begin{array}{l}\text { Double parentheses are used to give additional comments by the transcriber to describe } \\
\text { certain events: }((\text { cough })),((\text { clears throat })),((\text { pause })), \text { and other similar examples. }\end{array}$ \\
\hline (word) & $\begin{array}{l}\text { Whe } \\
(1) \\
(2) \\
(3) \\
(4)\end{array}$ & $\begin{array}{l}\text { en a word or phrase is in a parentheses, there are two possible explanations: } \\
\text { The word or phrase in a parentheses was uttered in an unclear manner, and the } \\
\text { transcriber attempts to provide the most likely possibility of the utterance. } \\
\text { The word or phrase in a parenthesis is the translation of the foreign (any language other } \\
\text { than English) word or phrase before the parenthesis. }\end{array}$ \\
\hline \multicolumn{3}{|c|}{$\begin{array}{l}\text { (alphabet) When there is a particular alphabet(s) in a parenthesis which is located in the middle or at the } \\
\text { end of a word, this shows that those alphabets are supposed to be pronounced in the word } \\
\text { but is not pronounced by the speaker. }\end{array}$} \\
\hline & $\begin{aligned} \text { Emp } \\
\text { tran }\end{aligned}$ & $\begin{array}{l}\text { oty parenthesis indicates that there is an utterance being said by the speaker; however, the } \\
\text { ascriber is unable to identify the word at all. }\end{array}$ \\
\hline
\end{tabular}


International Journal of Applied Linguistics \& English Literature

ISSN 2200-3592 (Print), ISSN 2200-3452 (Online)

Vol. 1 No. 7; November 2012 [Special Issue on Applied Linguistics]

\section{Results and discussion}

\subsection{Speech Disfluencies in English Oral Communication}

Based on the types of speech disfluencies identified by Shriberg (1994), all the types are found in the data except deletion. Aside from these identified disfluencies, two other types of disfluencies were found. These include stuttering, and false starts. Fillers are by far the most prominent type of disfluency during the communication among the students.

\section{Excerpt 1}

"Uh-h in my poin of view critical tinking skill is not taught in school in, school, an critical tinking skill have to $b-e, \boldsymbol{u h}-\boldsymbol{h}$, learn from de reading, fo example magazine $\boldsymbol{u h}$ - $\boldsymbol{h}$ from website or experiencing, in de life.. This is my, uh-h opinion about that."

There seems to be no consistency in terms of whether pauses are used after fillers - the pattern is unpredictable and is completely dependent on the English proficiency of the student. The frequency of the fillers are also unpredictable, it can either not appear at all or appear in very high frequency. As shown in the utterance below, the presence of the fillers is extremely prominent.

Excerpt 2

"In our conclusion, $\boldsymbol{u h}$ - $\boldsymbol{h}$ de tinking skill among studen ni- $\boldsymbol{u h h}$ studen $\boldsymbol{u h}$-h.. importan $\boldsymbol{u h}-\boldsymbol{h}$ deir skill $\boldsymbol{u h}$ - $\boldsymbol{h}$ uhh afte sh-e $\boldsymbol{u h}$-h afte $\boldsymbol{u h h}$ dey want to-o uh-h um-m, apply deir job. Uh-h tinking skill can improve deir $\boldsymbol{u h}$ - $\boldsymbol{h}$ attitude d-e $\boldsymbol{u h}$ - $\boldsymbol{h}$, $\boldsymbol{u h}$ - $\boldsymbol{h}$ confiden to talk when you $\boldsymbol{u h h}$ () $\boldsymbol{u h}$-h $d$-e, when she uhh when uh-h we uh-h.. interview to uh-h get de..."

Repetitions of single words and phrases also occurred in the oral communication of TOCIE candidates. Excerpt 3

"So I ting de problem-solving acti-activities is, really help, which can really help de students in-n future, an in de, in de working fields an, an so on"

Repetitions that are used to emphasize a point are not considered as a speech disfluency because it was used by the student on purpose.

Excerpt 4

“... dey read, but dey don ting, dey jus read read read read like dis only, so how it can promote de tinking skill."

Substitution of words occurred, not as frequently as filled pauses, but there seems to be a consistency in terms of the substitution of grammatical categories. Most of the words that are substituted were replaced with another word of the same grammatical category. This could mean that the student actually knows the correct grammatical form to use, but initially used a less appropriate word in that category. The disfluency of substitution mostly involved determiners and nouns; but there were also instances of the substitution of other grammatical categories. All the types of substitution that occurred are listed in Table 5.

Table 5. Occurences of the Substitution as a Speech Disfluency

\begin{tabular}{|c|c|}
\hline Substitution & Example \\
\hline \multirow{5}{*}{ Substitution of Determiners } & "... so dey will ting more in de in dis case." \\
\hline & $\begin{array}{l}\text { "Uh-h de opinion of candidate A, B, an E is jus same like d-e } \\
\text { focus my focus poin which is critical ..." }\end{array}$ \\
\hline & $\begin{array}{c}\text { "... source de problem dat's given by, by d-e by our supervisor } \\
\text { or, problem dat we face in our work are." }\end{array}$ \\
\hline & $\begin{array}{l}\text { "... problem solving is de bes way to, promote de tinking skill, } \\
\text { from dat from dere, studen, can involve in ..." }\end{array}$ \\
\hline & $\begin{array}{l}\text { "... what am I going to emphasize here is reading is de basic, is a } \\
\text { basic way for you to ..." }\end{array}$ \\
\hline \multirow[b]{2}{*}{ Substitution of Nouns } & "... an, an um-m by di-s kind dis type of umm ..." \\
\hline & $\begin{array}{l}\text { "... learn in our class our course, uhh which encourage studen } \\
\ldots .\end{array}$ \\
\hline
\end{tabular}


International Journal of Applied Linguistics \& English Literature

ISSN 2200-3592 (Print), ISSN 2200-3452 (Online)

Vol. 1 No. 7; November 2012 [Special Issue on Applied Linguistics]

\begin{tabular}{|c|c|}
\hline \multirow{3}{*}{ Substitution of Verbs } & $\begin{array}{l}\text { "... because, base on our own tought, our own belief, we need to } \\
\text { voice out dare to voice out an dis is de main point ..." }\end{array}$ \\
\hline & $\begin{array}{l}\text { "... dat's also a problem actually, but it jus not a big problem, } \\
\text { how I have to, how I going to school by ..." }\end{array}$ \\
\hline & "... uhh dey can dey are able to ting uhh out of de box an ..." \\
\hline \multirow{2}{*}{ Substitution of Adjectives } & $\begin{array}{l}\text { "So dey must to have uh-h some, reason dat uhh good reason } \\
\text { strong reason uhh to make sure ..." }\end{array}$ \\
\hline & $\begin{array}{ll}\text { "... } & \text { cos examination is when dey really tes you on how } \\
\text { knowledgeable, how much you know den uhh dey ..." }\end{array}$ \\
\hline Substitution of Adverbs & $\begin{array}{l}\text { "... read de texbook or read de internet article any any you jus } \\
\text { you can ..." }\end{array}$ \\
\hline
\end{tabular}

However, certain occurrences of substitution were not recognized as a speech disfluency because their usage in the utterance signify a form of accentuation and can be used deliberately by the speaker to emphasize a point to the listener.

Except 5

"So, what I am-m ah uhh agree wit candidate B dat uhh argumentative skills is importan to-o uhh promote tinking skills because you have to ting bef-befo you argue you have to know what is your poin what is your stan, to argue."

Insertions occurred for several reasons during the communication among the students such as to change a positive statement into a negative one, to add a verb, noun, or an adverb, to add a possessive determiner, or to make the following context more specific. All reasons for the occurrences of insertion are listed in Table 6 .

Table 6. Reasons for Insertions

\begin{tabular}{|c|c|}
\hline $\begin{array}{l}\text { Change a positive statement to a } \\
\text { negative one }\end{array}$ & $\begin{array}{l}\text { "If we have, if we doesn have any knowledge about some topic } \\
\text {..." }\end{array}$ \\
\hline Add a verb & $\begin{array}{l}\text { "... mus have some way or metod or even some courses to on, } \\
\text { to teach us on how to decide de right materials on } \\
\text { reading." }\end{array}$ \\
\hline Add a noun & $\begin{array}{l}\text { "... so dey can argue among demself den can learn about de } \\
\text { tinking skill a bit mo can be improve deir, tinking skill in } \\
\text { dis way, in dis kin(d) of way." }\end{array}$ \\
\hline Add an adverb & "... fo exam you jus, normally we jus, memorise an jus ..." \\
\hline Add a possessive determiner & $\begin{array}{l}\text { "An studen can uhh learn uh-h about new-w skill uh-h to-o to } \\
\text { sof problems uh-h, to sof deir problems." }\end{array}$ \\
\hline \multirow{2}{*}{ Specify the following context } & $\begin{array}{l}\text { "As we know d-e outcome of UPM one of the programme } \\
\text { outcome of UPM is de, de ability studen to tinking." }\end{array}$ \\
\hline & $\begin{array}{l}\text { "... if you are studen university studen, de focus on } \\
\text { examination is very importan ..." }\end{array}$ \\
\hline
\end{tabular}

Articulation errors should not be confused with mispronunciations as they are two different types of errors. Articulation errors are when a part of the word is articulated wrongly and the speaker then proceeds to correct the utterance of the word after realizing the mistake. Among the words that were articulated wrongly initially before being corrected were long words, 5 syllables in terms of word length. Those words were university, and examination (articulated wrongly twice by two different students). The word every, which can either be pronounced in two or three syllables, was articulated wrongly once, and one short word as, which is one syllable in length was also articulated wrongly once.

Articulation error of university:

"Okay uh-h ou(r) topic today is to promote tinking skills among unisty university studens ..."

Articulation error of examination: 
International Journal of Applied Linguistics \& English Literature

ISSN 2200-3592 (Print), ISSN 2200-3452 (Online)

Vol. 1 No. 7; November 2012 [Special Issue on Applied Linguistics]

“... so I ting examinen uhh examination is de way, to let de studens have uhh uhh to study themsef."

"Because of, in my opinion, I ting dat, exas- examination is a good way to promote de tinking skill."

Articulation error of every:

“... each an each an ery- every aspec is actually very importan it relates to each ..."

Articulation error of $a s$ :

“... uhh actually uhh we uh-h school should uh-h, ash, as uh-h each studen one by one about ..."

This shows that word length or the number of syllables in a word is a factor that can negatively affect the student's articulation. The longer the word, the more likely a student will articulate the word incorrectly in an utterance.

Unlike the occurrence of articulation errors, stuttering occur rather frequently for various word lengths. Most of the words that were stuttered are all different words except for the words critically, university, and candidate that were stuttered more than once by different students. The stuttering of words could be caused by the nervousness of the students when conversing with one another in front of the TOCIE examiners. In most cases of the occurrence of stuttering, students only made one stuttering mistake during one course of utterance, which is good because it shows that the disfleuncy is being controlled. Only during two courses of utterancesdid stuttering occurr twice, and during one course of utterance, stuttering occurred three times.

Only false starts that involve the abortion of words that are being uttered halfway and then restarted are considered in this research. False starts are quite common among the students and are often accompanied by filled pauses.

Speech disfluencies occurred also in combinations instead of in the form of isolated components. This means that several types of speech disfluencies occurred within the same phrase, making the utterance more interrupted and cluttered. Several forms of combinations were found: one of them is the combination of substitution and insertion. This shall be called a bi-disfluency since it is two disfluencies combined together. An example of the occurrence of a bi-disfleuncy is in so I ting examinen uhh examination is de way whereby there is an articulation error of the word examination and there was also the filler uhh together within the same phrase. Another bi-disfluency can be seen in ex-, uhh examiner or interviewer whereby again a filled pause is combined with the stuttering of examiner. The types of bi-disfluency that occurred are shown in Table 7.

Table 7. Occurrences of Bi-Disfluency

\begin{tabular}{|l|l|l|}
\hline \multicolumn{1}{|c|}{ Bi-Disfluency } & \multicolumn{1}{c|}{ Word } & \multicolumn{1}{c|}{ Example } \\
\hline $\begin{array}{l}\text { Filled Pause } \\
\text { Articulation Error }\end{array}$ & $\begin{array}{l}\text { uhh } \\
\text { examination }\end{array}$ & “... so I ting examinen uhh examination is de way ...” \\
\hline $\begin{array}{l}\text { Filled Pause } \\
\text { Stuttering }\end{array}$ & $\begin{array}{l}\text { uhh } \\
\text { examiner }\end{array}$ & “... ex-, uhh examiner or interviewer ...” \\
\hline $\begin{array}{l}\text { Filled Pause } \\
\text { Repetition }\end{array}$ & $\begin{array}{l}\text { uhh } \\
\text { go alongs }\end{array}$ & "... go alongs, go uhh alongs ...” \\
\hline $\begin{array}{l}\text { Repetition } \\
\text { Substitution }\end{array}$ & $\begin{array}{l}\text { by } \\
\text { d-e, our }\end{array}$ & “...given by, by d-e by our supervisor .... \\
\hline $\begin{array}{l}\text { Substitution } \\
\text { Insertion }\end{array}$ & $\begin{array}{l}\text { you, we } \\
\text { normally }\end{array}$ & “... fo exam you jus, normally we jus .... \\
\hline
\end{tabular}

It can be noticed that filled pauses are usually part of bi-disfluencies because they are easily inserted into any part of the sentence, even within another occurrence of disfluency. The addition of a disfluency with another causes more distortion to the utterance and makes the speaker sound less proficient in the language. It implies that one is uncomfortable and very uncertain about one's own use of the language, which will project a bad impression of oneself to the listener. The combination of repetition and substitution is acknowledged as a form of bi-disfluency only if there is the repetition of a particular word and not just the presence of a substitution. This means that if the utterance was given by d-e by our supervisor then it would only be a substitution form of speech disfluency; however, with the repetition of the word $b y$, then it is converted into a bi-disfluency. 


\section{International Journal of Applied Linguistics \& English Literature}

ISSN 2200-3592 (Print), ISSN 2200-3452 (Online)

Vol. 1 No. 7; November 2012 [Special Issue on Applied Linguistics]

There are also a few occurrences of a combination of three speech disfluencies, which will be called a tri-disfluency. Tri-disfluencies are more disruptive to one's flow of speech and may even cause the speaker to sound nonsensical. Table 8 shows the occurrences of tri-disfluency.

Table 8. Occurrences of Tri-Disfluency

\begin{tabular}{|l|l|l|}
\hline \multicolumn{1}{|c|}{ Bi-Disfluency } & \multicolumn{1}{c|}{ Word } & \multicolumn{1}{c|}{ Example } \\
\hline Repetition & what & “... what, uh-h de what dey talks ...” \\
Insertion & $d e$ & \\
Filled Pause & $u h-h$ & “... de s- de uhh mo- how to say ...” \\
\hline Repetition & $d e$ & \\
False Start & $s-$, mo- & \\
Filled Pause & $u h h$ & \\
\hline
\end{tabular}

\subsection{Mispronunciations in English Oral Communication}

There are several words that were mispronounced by the TOCIE candidates and there are listed in Table 9.

The words have been categorized according to the sound that has been replaced or omitted. Other than those words that were pronounced wrongly by different students frequently, there were a few unusual cases of mispronunciation that only occurred once. Since they only occurred once per word, it is safe to assume that those words were articulated wrongly unintentionally and the student probably did not even realise that the error was made, which might explain why the student did not correct the error. These mispronunciations include $s p e e s h$, crucious, asgree, and prosediu.

Table 9. Examples of Occurrences of Mispronunciation

\begin{tabular}{|c|c|c|c|}
\hline & Word & Correct Pronunciation & Mispronunciation \\
\hline Replacement of vowels & Faculty & /'fæk(ə)lti/ & /fa:kolti/ \\
\hline Replacement of /dz/ & Graduate & /grædzuət/ & /græduət/ \\
\hline \multirow{17}{*}{ Omission of Sounds } & Ask & /a:sk/ & /a:s/ \\
\hline & For & $/ \mathrm{f} \mathrm{g}:(\mathrm{r}) /$ & /fo:/ \\
\hline & Before & /bifo:(r)/ & /bifo:/ \\
\hline & More & /mo:(r)/ & /ms:/ \\
\hline & Best & /best/ & /bes/ \\
\hline & Argument & /a:(r)gjumənt/ & /a:(r)gjumən/ \\
\hline & Different & /difrənt/ & /difrən/ \\
\hline & Important & /Impo:(r)t(ə)nt/ & /Impo:tən/ \\
\hline & Student & /stju:d(ə)nt/ & /stu:dən/ \\
\hline & Just & /dz $3 \Lambda \mathrm{st} /$ & $/ \mathrm{d} 3 \Lambda \mathrm{s} /$ \\
\hline & Attract & /otrækt/ & /atræk/ \\
\hline & Product & $/ \mathrm{prod} \Lambda \mathrm{kt} /$ & $/ \operatorname{prod} \Lambda \mathrm{k} /$ \\
\hline & Aspect & /æspekt/ & /æspek/ \\
\hline & Subject & /sıbdzIkt/ & /sıbdzek/ \\
\hline & Accept & /oksept/ & /2ksep/ \\
\hline & Point & /point/ & /poin/ \\
\hline & Textbook & /teks(t)bok/ & /teksbuk/ \\
\hline \multirow{6}{*}{ Replacement of $/ \theta /$} & Method & $/ \mathrm{me} \theta \partial \mathrm{d} /$ & $/ \mathrm{met} \partial \mathrm{d} /$ \\
\hline & Theory & /Orəri/ & /tıri/ \\
\hline & Three & /Ori:/ & /tri:/ \\
\hline & Through & /Oru:/ & /tru:/ \\
\hline & Think & $/ \theta \mathrm{ink} /$ & /tink/ \\
\hline & Thinking & /Oinkın/ & /tinkin/ \\
\hline \multirow{4}{*}{ Replacement of /ð/ } & The & /ðə/ & /də/ \\
\hline & This & /ðIS/ & /dis/ \\
\hline & Rather & / ra:ðə(r)/ & / ra:də/ \\
\hline & Their & /ठеә(r)/ & $/ \mathrm{de} /$ \\
\hline
\end{tabular}


International Journal of Applied Linguistics \& English Literature

ISSN 2200-3592 (Print), ISSN 2200-3452 (Online)

Vol. 1 No. 7; November 2012 [Special Issue on Applied Linguistics]

\begin{tabular}{|c|c|c|c|}
\hline & Then & /ðen/ & /den/ \\
\hline & They & /ðеI/ & /deI/ \\
\hline & Either & /аıðә(r)/ & /aIdə/ \\
\hline & Together & /təgeðə(r)/ & /tugedə/ \\
\hline & Whether & /weðə(r)/ & /wedə/ \\
\hline & Other & /ムðə(r)/ & $/ \Lambda \mathrm{d} \partial /$ \\
\hline & With & /WIð/ & /wIf/ \\
\hline Replacement of /v/ & Solve & /splv/ & /spf/ \\
\hline
\end{tabular}

\subsection{Linguistic Factors that Influence the Occurence of Mispronunciations in English Oral Communication}

The replacement of $/ \theta /$ with $/ t /$ is expected from speakers who speak Malay and Mandarin as their first language. According to the Theory of Language Transfer, since there is no $/ \theta /$ in both of these languages, negative transfer occurs and another sound from the speakers' native language is used to substitute the $/ \theta /$. In the Malay and Mandarin languages, the closest sound to $/ \theta /$ would be $/ t /$ because $/ \theta /$ is a voiceless sound like $/ t /$. Therefore, for example, through is pronounced as /tru:/ instead of / $\theta \mathrm{ru} / /$. In the same way, the voiced / $/$ / is also non-existent in both of these languages and it is replaced with another voiced sound $/ \mathrm{d} /$. These replacements of $/ \theta /$ and $/ \delta /$ support the findings of Major and Faudree (1996) who also noticed that Chinese speakers face problems in pronouncing $/ \theta /$ and $/ \delta /$.

In the replacement of $/ \mathrm{d} 3 /$ in the word graduate with $/ \mathrm{d} /$, the Theory of Language transfer cannot be used as a means to explain the mispronunciation because / $\mathrm{d} 3 /$ also exists in both the Malay and Mandarin language. However, in the Malay and Mandarin language, the orthographic $d$ can only represent one sound, which is $/ \mathrm{d} /$, unlike in English where the same orthographic symbol can be used for /dz/. Therefore, a non-native speaker of English will automatically pronounce it as such instead of the correct pronunciation. The Malay language also uses a similar sounding word to mean the same definition as graduate, which is graduan. Since the words are nearly similar, it is natural for the Malay speakers to use the same pronunciation for the first syllable for the word and only change the second syllable.

The orthographic $a$ and $u$ in the Malay language only represents one sound, unlike in the English language. Words like faculty will then be pronounced as /fa:kulti/ seeing as there is the same Malay version of the word as well, fakulti with again is nearly of the same spelling.

Overlapping of sounds in both the Malay and English language is rather common because the borrowing of English words do occur in the Malay language. Words like product, aspect, and subject, for example, all have the Malay language counterparts: produk, aspek, subjek. In all of these Malay words, the last sound is $/ \mathrm{k} /$ and not /t/ in English, since Malay speakers are used to pronouncing it in their first language, they tend to omit the last sound and mispronounce the English word. In the Mandarin language, most sounds do not end with a consonant; the few consonants that are present in the last syllable is $/ \mathrm{n} /$ and $/ \mathrm{n} /$. This might explain the frequent omissions of last sounds in words like argument, different, and important. The $/ \mathrm{n} /$ is pronounced since $/ \mathrm{n} /$ is a frequent last sound in the Mandarin language, but then the $/ \mathrm{t} / \mathrm{is}$ overlooked and not pronounced.

The $/ \mathrm{v} /$ phone is another rare sound in the Malay language and a non-existent sound in the Mandarin language. In Standard Malay, $/ \mathrm{v} /$ is not used unless it is from a borrowed word; therefore, the sound is not native in nature. It is then replaced with another labio-dental fricative sound, /f/. Words like solve are then pronounced as /spf/.

Therefore, through these results, it is obvious that a learner's first language has a heavy influence on the second-language production. Sound systems that are in the L1 and L2 are unconsciously processed in a learner's language knowledge and adaptations are made when a particular sound does not exist or rarely occur in the L1.

\section{Conclusion}

This study sought to investigate the type of speech disfluencies, and mispronunciations that occur in English oral communication among UPM undergraduates and also the linguistic factors that contribute to the mispronunciations. Results show that the types of disfluency that occur are filled pauses, repetitions, substitutions, insertions, articulation errors, stuttering, and false starts. It is also noticed that in more serious cases, two or three disfluencies can occur together, forming bi-disfluency or tri-disfluency respectively, which further shows the degradation of the English oral proficiency of the undergraduates. Mispronunciations are very common; however, the occurrences of mispronunciations are predictable as they support the Theory of Language Transfer, which makes it easier to understand the reason behind the mispronunciations. 
International Journal of Applied Linguistics \& English Literature

ISSN 2200-3592 (Print), ISSN 2200-3452 (Online)

Vol. 1 No. 7; November 2012 [Special Issue on Applied Linguistics]

The Critical Period Theory should be used as a cornerstone for parents to expose their children to other languages beside their first language when they are still young so that they may get an earlier grasp of the languages. Besides the role of the parents at home, the teachers have to be more aware of the speech disfluencies and mispronunciations that their students are making and give more attention to correcting those errors in a non-intimidating way. In-class grammar, pronunciation, and vocabulary exercises should not be only limited to younger students, but also students at the tertiary level because currently even university students are still struggling with those same errors.

The findings of this study provides an understanding of the errors that are occurring so that both students and teachers can be more aware of them and instead of taking those errors lightly, they should take the next step to correct them or at least begin by decreasing the frequency of those errors. Achieving native-like oral fluency in the English language is undeniably a difficult and long process, and even more so for those who do not speak English as their first language and are more influenced by their native language. However, with the correct measures, constant practice, and the willingness to learn, it is not impossible to improve the level of oral proficiency and stand a better chance in the international arena.

\section{References}

Andrews, N. (2006). Sound and fury. Financial Times, 15 April 2006, 22.

Baars, B., Motley, M., \& MacKay, D. (1975). Output editing for lexical status from artificially elicited slips of the tongue, Journal of Verbal Learning and Verbal Behaviour, 14, 382-391.

Baskaran, L. (1994). The Malaysian English mosaic. English Today, 37, 27-32.

Benson, P. (1990). A language in decline? English Today, 6(4), 19-23.

Bizzell, P. (1989). Review of the book: The Social Construction of Written Communication. College Composition and Communication, 40, 483-486.

Bonaventura, P., Herron, D., \& Menzel, W. (2000). Phonetics rules for diagnosis of pronunciation errors. Tagungsband 5. Konferenz Verarbeitung natürlicher Sprache, Konvens 2000, Ilmenau, S., 225-230.

Cenoz, J., \& Lecumberri, M. L. G. (1999). The acquisition of English pronunciation: Learners' views. International Journal of Applied Linguistics, 9(1), 3-18.

Cook, V. J. (2003). The effects of the second language on the first. Clevedon: Multilingual Matters.

Crossing, G., \& Ward, I. (2002). Oral Communication: the workplace needs and uses of business graduate employees. English for Specific Purposes, 21(1), 41-57.

Dell, G. S. (1986). A spreading-activation theory of retrieval in sentence production. Psychological Review, 93(3), 283-321.

Donselaar, W. V. (1996). Mispronunciation detection. Language and Cognitive Processes, 11(6), 621-628.

Eckman, F. (1977). Markedness and the contrastive analysis hypothesis. Language Learning, 27(2), 315-330.

FBMK. (2011). UPM Test on Communication in English (UPM-TOCIE). Retrieved November 21, 2001, from http://www.fbmk.upm.edu.my/TOCIE/

Flege, J. E. (1993). Production and perception of a novel, second-language phonetic contrast. Journal of the Acoustical Society of America, 93(3), 1589-1608.

Fox Tree, J. E. (1995). The effects of false starts and repetitions on the processing of subsequent words in spontaneous speech. Journal of Memory and Language, 34(6), 709-738.

Fu, J. S. (2010). A comparison between Taiwanese ESL learners' perception and production of English pronunciation (Doctoral dissertation). Available from Dissertations and Theses database. (UMI Number: 3426660)

Gass, S. M., \& Selinker, L. (1972). Second language acquisition: An introductory course. Mahwah, N.J: Lawrence Erlbaum Associates.

Heritage, J., \& Clayman, S. (2010). Talk in action: Interactions, identities, and institutions. Chichester, U.K: Wiley-Blackwell. 


\section{International Journal of Applied Linguistics \& English Literature}

ISSN 2200-3592 (Print), ISSN 2200-3452 (Online)

Vol. 1 No. 7; November 2012 [Special Issue on Applied Linguistics]

Hughes, I. E. \& Large, B. J. (1993). Staff and peer-group assessment of oral communication skills. Studies in Highes Education, 18(3), 379-385.

Jobstreet. (2009). Survey: The importance of the English language in the workplace. Retrieved November 20, 2011 from http://www.jobstreet.com.my/announcement/2009/d/survey.htm

Kachru, B. (1986). The alchemy of English: The spread, functions and models of non-native Englishes. Oxford: Pergamon Press.

Komunitikini. (2011). Hanya 65 peratus graduan UPM dapat kerja tahun lepas [Only 65 percent of UPM graduates were employed last year]. Retrieved November 20, 2001, from

$\mathrm{http} / / /$ komunitikini.com/kl-selangor/serdang/hanya-65-peratus-graduan-upm-dapat-kerja-tahun-lepas

Lado, R. (1957). Linguistics across culture. Ann Arbor: University of Michigan Press.

Lee, E. S., Forthofer, R. N., \& Lorimer, R. J. (1989). Analyzing complex survey data. London: Sage Publications.

Lenneberg, E. H. (1967). Biological foundation of language. New York: Wiley.

Major, R. C., \& Faudree, M. C. (1996). Markedness universals and the acquisitions of voicing contrasts in Korean speakers of English. Studies in Second Language Acquisition, 18(1), 69-90.

Marslen-Wilson, W. D., \& Tyler, L. K. (1980). The temporal structure of spoken language understanding. Cognition, 8, 1-71.

McArthur, T. (1998). The English languages. Cambridge: University Press.

Phillip, S., Pillai, S., \& Jeyam, L. (2007). Identity in context: Literary and cultural studies in Malaysia and Singapore. Proceedings of the First Asia POSCO Forum 2007.

Pillai, S., Knowles, G., \& Mohd. Don., Z. (2001). Towards building a model of standard Malaysian English pronunciation. In Mohd. Don. Z., (Ed.), ELT Research and Pedagogy in Malaysia: The Way Forward.

Platt, J., Weber, H., \& Ho, M. L. (1984). The new Englishes. London: Routledge \& Kegan Paul.

Postma, A., Kolk, H. H. J., \& Povel, D. J. (1990). On the relation between speech errors, disfluencies, and self-repairs. Language and Speech, 33, 19-29.

Rajadurai, J. (2004). The faces and facets of English in Malaysia. English Today, 20, 54-58.

Samuel, B. L., \& Leah, E. R. V. (1979). That forgotten basic skill: Oral communication. University of Iowa, Iowa, United States.

Scollon, R., \& Scollon, S. (1995). Intercultural communication. Oxford: Blackwell.

Shriberg, E. (1994). Preliminaries to a theory of speech disfluencies. PhD. dissertation, University of California, Berkeley.

Silverberg, S., \& Samuel, A. G. (2004). The effect of age of second language acquisition on the representation and processing of second language words. Journal of Memory and Language, 51. 381-398.

Simon, E. \& Taverniers, M. (2011). Advanced EFL learners' beliefs about language learning and teaching: A comparison between grammar, pronunciation, and vocabulary. English Studies, 92(8), 896-922.

Strevens, P. (1992). English as an international language: Directions in the 1990s. In Kachru B. B., (Ed.), The other tongue: English across cultures ( $2^{\text {nd }}$ ed.), 27-47. Urbana: University of Illinois Press.

Toolan, M. (1997). Recentering English: New English and global. English Today, 52, 3-10.

Van Horn, C. E. (1995). Enhancing the connection between higher education and the workplace: A survey of employers. Denver, CO: State Higher Education Executive Officers Association.

Van Weeren, J., \& Theunissen, T. J. J. M. (1987). Testing pronunciation: An application of generalizability theory. Language Learning, 37(1), 109-122.

Weisberg, H. F., Krosnik, J. A., \& Bowen, B. D. (1989). Cognitive processes underlying context effects in attitude measurement. Psychological Bulletin, 103, 299-314. 